Pure Appl. Chem., Vol. 76, No. 4, pp. 707-722, 2004.

(C) 2004 IUPAC

\title{
Why liquid membrane extraction is an attractive alternative in sample preparation*
}

\author{
Luke Chimuka $^{1, \ddagger}$, Ewa Cukrowska², and Jan Åke Jönsson ${ }^{3}$ \\ ${ }^{1}$ Department of Ecology and Resource Management, School of Environmental \\ Science and Engineering, University of Venda for Science and Technology, \\ P/Bag X5050, 0950, Thohoyandou, Limpopo Province, South Africa; ${ }^{2}$ School of \\ Chemistry, University of the Witswatersrand, Private Bag 3, Wits 2050, \\ Johannesburg, South Africa; ${ }^{3}$ Department of Analytical Chemistry, Lund University, \\ P.O. Box 124, S-22100 Lund, Sweden
}

\begin{abstract}
The use of liquid membrane-based extractions is increasingly seen as offering an alternative to conventional sample preparation procedures in analysis of chemical species in both environmental and biological media. In this article, emphasis is placed on the attractiveness of liquid membrane-based extraction techniques to a variety of analytical applications such as speciation of metal ions in biological fluids, time-weighted average field sampling, and time-weighted average passive field sampling. Further, the area of designing new and much simpler miniaturized configurations, which is enjoying much attention in liquid membrane-based extraction techniques, is discussed.
\end{abstract}

\section{INTRODUCTION}

Many analytical techniques and methods have been developed for analysis of various pollutants in environmental and biological samples. Despite these achievements in analytical science, there are still challenges. One challenge lies in determining pollutants in various complex matrices such as plant extracts, sediments, and biological fluids. Most developed analytical methods require several steps consuming time and solvents. In ecological risk assessment for chemical pollutants, it is important to quantify the concentrations of freely dissolved in aqueous samples for approximate characterization of the bioavailable fraction. Determining the concentration of pollutants freely dissolved in complex matrices as plant extracts and biological fluids is even more challenging, especially for metal ions. There are not many techniques/methods available that can be used for speciation studies of metal ions in biological fluids. The challenge of chemical analysis, especially speciation studies, and determining the freely dissolved pollutants in a complex sample is staggering. Moreover, components of interest exist at trace levels. These challenges have made sample preparation become a key step in modern chemical analysis. It is an essential part of any analytical procedure because of the following reasons: sample preconcentration or enrichment and removal of contaminants.

The most widely used sample preparation techniques are liquid-liquid extraction (LLE) [1] and solid-phase extraction (SPE) [2]. LLE is the traditional technique for extraction of organic analytes from aqueous solutions. The basis is the partitioning of the dissolved analytes between the organic phase (extraction liquid) and the aqueous solution (sample solution) according to their partition coefficients. Further shifting the equilibrium toward the organic phase brings about increased enrichment in

\footnotetext{
*Plenary lecture presented at the Southern and Eastern Africa Network of Analytical Chemists (SEANAC), Gaborone, Botswana, 7-10 July 2003. Other presentations are published in this issue, pp. 697-888.

${ }^{\ddagger}$ Corresponding author: Fax: +27 (015) 9628597; E-mail: luke_chimuka@hotmail.com
} 
the organic phase. This can be achieved by addition of a salt to the aqueous phase. Alternatively, or additionally, the extraction is repeated several times. Ensuring that target analytes have large partition coefficients compared to possible interference controls the selectivity of the extraction. Thus, selectivity can be fine-tuned by changing the polarity of the organic solvent, using ion pairing or $\mathrm{pH}$ adjustments in the aqueous phase. The technique is well known and still widely used, although now it is less attractive and is being replaced by other techniques. This is because LLE (i) is tedious and time-consuming, especially when extracting aqueous complex samples such as plant extracts and sediments, which demands many steps before a clean extract is obtained; (ii) is not easy to automate; (iii) forms emulsions which at times makes it difficult to separate the two phases; and (iv) is environmentally unfriendly due to large volumes of organic solvents used. However, with LLE, large enrichment factors can be obtained despite the cited drawbacks.

SPE techniques are perhaps the most popular in sample preparation especially for organic analysis. However, most official methods still use LLE techniques such as those published by the U.S. Environmental Protection Agency (USEPA). The principle of SPE is based on sorption of analytes on a sorbent. The aqueous sample solution passes the SPE column, and the analytes are first trapped on the sorbent and then eluted with a suitable small volume of organic solvent. Extraction and enrichment of the analytes is thereby simultaneously achieved. Most sorbents are now available as disks, cartridges, or precolumns [3,4]. The use of SPE for environmental and biomedical applications, including details of its principles, is well documented in many review papers [2,5-7] and books $[1,8]$. Recent research has been directed toward developing sorbents that are capable of trapping polar analytes (graphitized carbon blacks and functionalized polymers) and selective sorbents (molecularly imprinted polymers and immunosorbents) suitable for complex matrices such as wastewater, foodstuffs, and plant extracts [2]. This is because the common sorbents, especially $n$-alkyl bonded silica sorbents, are both nonselective and give low breakthrough volumes for polar analytes. Another related technique to SPE that is now getting widespread attention in many laboratories is solid-phase microextraction (SPME), which is easily connected to gas chromatography in an automated way and uses little or no organic solvent. It has recently been reviewed for environmental applications [9]. However, despite its simplicity, it lacks selectivity when extracting analytes in complex matrices such as plant extracts, foodstuffs, and wastewater.

Publications dealing with membrane-based extraction techniques in sample preparation are on the increase as reported in the review articles and book chapters [10-16]. For the first, a special journal issue devoted to the use of membrane-based extractions in analytical chemistry was published [17]. An area enjoying much attention by various research groups is developing membrane-based extraction techniques that are simple, cheap, and miniaturized [18-28].

\section{MEMBRANE-BASED SAMPLE PREPARATION}

The main membrane techniques that have been used for analytical applications can be classified based on whether the membrane is porous or nonporous during the extraction of the sample solution [16]. A clear difference between these two is that selectivity for porous membrane processes is mainly based on pore size and pore size distribution. A nonporous membrane can be either a porous membrane impregnated with a liquid or entirely a solid, like silicone rubber. In both of these cases, the chemistry of the membrane material can influence the selectivity and the flux of the process [18]. This review will focus on liquid membrane extraction techniques whereby a porous membrane is impregnated with a liquid. 


\section{Other membrane-based extraction techniques}

\section{Dialysis and electrodialysis}

In dialysis, solutes diffuse from the aqueous donor side of a porous membrane to the aqueous receiving side as a result of a concentration gradient. Separation between the solutes is obtained as a result of differences in diffusion rates arising from differences in molecular size. Dialysis is therefore most effective in removing large molecules like proteins from small ones $[18,29]$. It is a technique that has few applications for environmental analysis except in biological samples since in the former, both the analytes and the sample matrix compounds are small molecules. The analytes are also continually diluted in the acceptor unless a precolumn is incorporated [30]. Electrodialysis technique tries to redress the drawbacks of dialysis in environmental analysis, viz. its nonselectivity and the dilution of the analytes in the receiving phase. It is a porous membrane technique whose separation power relies on differences in molecular size of the compounds and also on their charges. The electrical potential applied across the separation membrane makes sure that properly charged analytes in the feed solution are drawn through the membrane to the receiving side [31]. With a flowing feed solution and stagnant receiving phase, additional selectivity and enrichment of charged analytes can be obtained. The basic principles of electrodialysis for trace analysis have been reviewed by Debets et al. [19]. It has its own limitations such as limited enrichment factors, $\mathrm{pH}$ change in the feed during extraction, and thermal degradation of the membrane at high potential [31]. The cited problems make electrodialysis less attractive for analytical applications.

\section{Polymeric membrane extraction (PME)}

In this case, instead of a porous membrane, an entirely solid membrane is used to separate the donor and the acceptor solutions. Silicone rubber is mostly used because it is hydrophobic and gives high permeability for small hydrophobic molecules [32]. The difference in the solubility and diffusion of various analytes into the polymer is the basis of selectivity. Changing conditions in the acceptor phase, such as making sure that analytes ionize, can enhance the selectivity [20]. This condition is a similar requirement as in supported-liquid membrane extraction technique as described below. Its major advantage is that the solid nature of silicone rubber means that phase breakthrough is minimized. The major disadvantage is that it does not allow for any room to incorporate other functional groups (carriers) that can enhance both the mass transfer and the selectivity of the compounds of interest. The solid nature of silicone rubber nonetheless makes it a versatile technique as it allows aqueous [33], organic [20], and gaseous samples to be processed (see below). It is an especially ideal method for extracting analytes in complex samples with high amounts of organic materials such as lipids [34] since the instability associated with liquid membranes does not exist. It also allows various versions of phase combinations for extraction (Table 1). In all the combinations, the partitioning of the analytes into the polymer, diffusion through it, and partitioning into the receiving phase are important critical factors that influence the overall mass-transfer coefficient $[32,35]$.

\section{Membrane extraction with a sorbent interface (MESI)}

The technique is based on membrane extraction into a gas followed by trapping of the analytes on a solid sorbent (cryofocusing) and subsequent thermal desorption into a gas chromatographic system [36]. The technique is therefore suitable for volatile organic compounds either in air or aqueous samples. The receiving phase is always a carrier gas that continuously strips off and transports the analytes on the sorbent. The detailed theory of the technique and the type of sorbents that are used to trap the analytes have been described by Pawliszyn et al. [37] and Harper [38], respectively. The basis of selectivity of the method is differences in solubility and diffusion of various analytes into the nonporous polymer. The main drawback of the technique is that it has a narrow application window for environmental analysis; only volatile organic compounds can be extracted. Pawliszyn et al. recently developed a method for analysis of volatile breath components using membrane extraction with a sorbent interface [39]. 
Table 1 Different major membrane techniques used in analytical applications [10,11].

\begin{tabular}{|c|c|c|c|}
\hline Name & Abbreviation & Type & $\begin{array}{l}\text { Phase combinations used } \\
\text { Donor/membrane/acceptor }\end{array}$ \\
\hline Dialysis & - & Porous membrane & $\mathrm{Aq} / \mathrm{membrane} / \mathrm{Aq}$ \\
\hline Electrodialysis & ED & Porous membrane & $\mathrm{Aq}$ \\
\hline $\begin{array}{l}\text { Supported-liquid membrane } \\
\text { extraction }\end{array}$ & SLM & Nonporous membrane & $\mathrm{Aq} / \mathrm{org} / \mathrm{aq}$ \\
\hline $\begin{array}{l}\text { Microporous membrane } \\
\text { liquid-liquid extraction }\end{array}$ & MMLLE & Nonporous membrane & Aq/org/org \\
\hline $\begin{array}{l}\text { Semipermeable membrane } \\
\text { devices }\end{array}$ & SPMDs & Nonporous membrane & Aq/polymer/org \\
\hline $\begin{array}{l}\text { Polymeric membrane } \\
\text { extraction }\end{array}$ & PME & Nonporous membrane & $\begin{array}{c}\text { Aq/polymer/aq, } \\
\text { org/polymer/aq, } \\
\text { aq/polymer/org }\end{array}$ \\
\hline $\begin{array}{l}\text { Membrane extraction with } \\
\text { sorbent interface }\end{array}$ & MESI & Nonporous membrane & $\begin{array}{l}\text { Gas/polymer/gas, } \\
\text { liquid/polymer/gas }\end{array}$ \\
\hline
\end{tabular}

\section{Semipermeable membrane devices (SPMDs)}

In SPMDs, hydrophobic organic analytes passively diffuse from aqueous donor phase through a polymeric membrane such as polyethylene into the acceptor phase filled with a thin film of a synthetic lipid such as triolein [40-43]. It is, therefore, used as a time-weighted passive field sampler. It is an important technique in exposure risk assessment of pollutants since it provides truly dissolved and bioavailable time-weighted average pollutant concentrations over longer periods. Generally, this technique is suitable for extraction of hydrophobic nonpolar compounds such as polycyclic aromatic hydrocarbons [44], chlorinated pesticides [40], and polychlorinated biphenyls [45] with partition coefficients $\left(\log K_{\text {ow }}\right)$ in the range 3.0-6.0 [12]. SPMDs are also not very selective as they rely on the differences in solubility and diffusion of the various analytes into the membrane and lipid. This necessitates additional clean-up of the extracts [46], consuming time and organic solvents. For quantitation, very little data is available for sampling rates of various pollutants into the SPMDs [44], making it difficult to estimate accurately the true concentrations of analytes in the original environmental compartment. This setback is being investigated via the addition of so-called permeability reference compounds (PRCs) to SPMDs lipid prior to sampling. This provides an overall correction factor for variation in uptake sampling rates.

\section{Supported-liquid membrane (SLM) extraction}

In an SLM extraction, an organic solvent is immobilized in the pores of an inert support material, separating the aqueous donor and the acceptor phases (Fig. 1). The analytes are partitioned from the aqueous sample stream into the organic membrane and are then re-extracted into the aqueous acceptor phase. The driving force is the difference of the analyte concentration between the donor and acceptor phases. In order to maintain the concentration gradient across the two phases, the solutes must be able to exist in two forms: in a nonionic form on the donor side to be extracted into the membrane and in an ionic form on the acceptor side in order to be irreversibly trapped. This is most simply achieved by $\mathrm{pH}$ adjustments in the two aqueous phases, and the method is, therefore, particularly well suited for ionizable compounds such as medium-to-weak acids and bases. SLM extraction can provide very selective enrichment. Selectivity can be fine-tuned by proper choice of the conditions in the three phases as seen in Fig. 1. This creates a selectivity window such that by the time the analytes are enriched in the acceptor phase, an indirect structural recognition is achieved and only analytes belonging to the same family are generally trapped at a time. Macromolecules are discriminated on the basis of their size while charged 


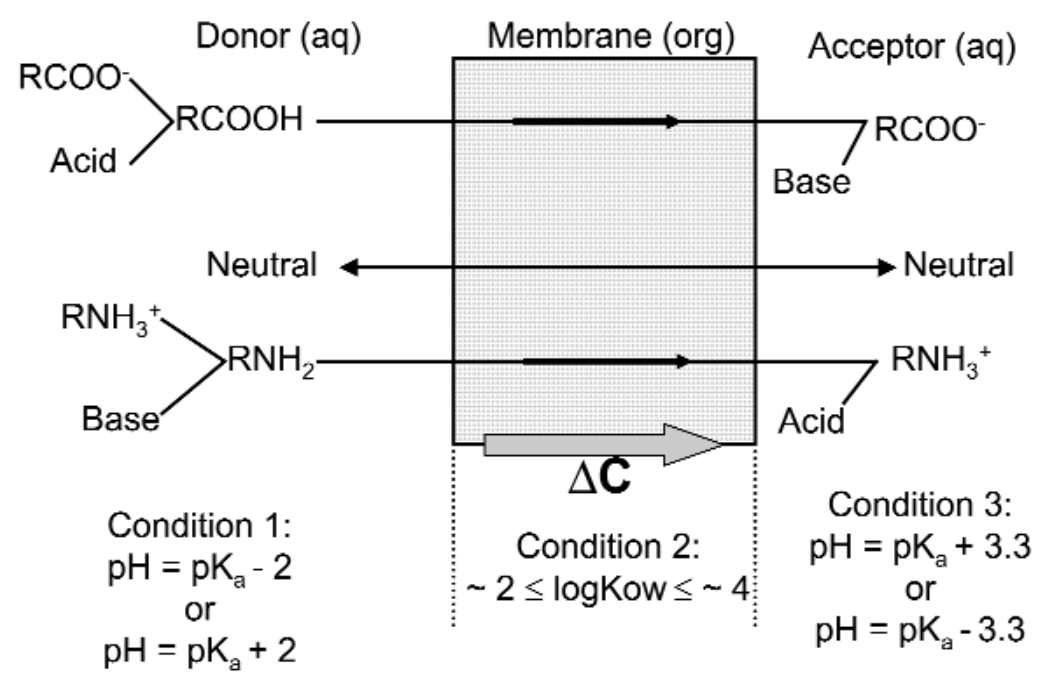

Fig. 1 Principles of SLM extraction of ionizable organic compounds where the transport mechanism is simple permeation. With permission from Elsevier [56,115].

compounds are too polar to dissolve into the organic liquid. Neutral molecules merely distribute between the three phases without any enrichment.

Often, selective transport based on relative differences in solubility in the membrane and trapping in the acceptor phase may be difficult to achieve. In another case, the solubility of the analyte may be too low to give efficient extraction even when the trapping in the acceptor can easily be realized. A good approach in such a case is to incorporate a mobile carrier into the membrane that selectively binds the analytes. The idea of incorporating a carrier also allows SLM extraction to be applicable to a variety of compounds such as permanently charged chemical species like metal ions. It also gives different versions of carrier-mediated transport mechanisms such as simple carrier transport (with chemical reaction in the acceptor), coupled co-transport [47,48], and coupled counter-transport [22,48-52]. In simple carrier transport, the carrier in the membrane forms a complex with the analyte in the donor that diffuses to the acceptor, where the analyte is converted to a nonextractable form. This type of transport was used in the extraction of short chain aliphatic carboxylic acids from acidic donor solution to an alkaline acceptor solution with liquid membrane containing tri- $n$-octylphosphine oxide (TOPO) as a neutral carrier [53]. Charged carriers can be used, such as the anionic di-(2-ethylhexyl) phosphoric acid (DEHPA) $[22,50]$. In such a case, dissolution of the analyte into the membrane occurs through ionic interactions with the charged carrier. Once the analyte reaches the acceptor phase, it is exchanged for a proton and converted to a nonextractable form. The proton gradient across the membrane in this case is the driving force [50]. This is an example of a coupled counter-transport mechanism.

The various factors that influence the extraction process have been covered by Jönsson et al. $[14,54]$. These include trapping in the acceptor phase, solvation power of the membrane and donor flow rate besides other factors such as membrane thickness, geometry of the donor, and acceptor channels of the SLM module. The trapping in the acceptor phase is seen as critical and is desirable that analytes are virtually ionized, otherwise extraction efficiency is not constant and decreases with time [55]. The solvation power of the membrane should give large analyte partition coefficients $\left(K_{\mathrm{D}}\right)$, but studies have shown that too high $K_{\mathrm{D}}$ values result in slow release into the acceptor phase [56]. At lower donor flow rates, the contact time of the analytes with the membrane is longer so highest extraction efficiencies are obtained. The extraction efficiency, $E$, is defined as the fraction of analyte extracted from the donor phase to the acceptor phase. It is a measure of the rate of mass transfer through the membrane and is constant at specified extraction conditions. At high donor flow rates, the extraction efficiency decreases 
as the contact time of the analytes with the membrane reduces. However, for moderately polar analytes (with $\log K_{\mathrm{ow}}>2$ ), high donor flow rates results into an increase in high enrichment factors since the amount extracted per unit time increases [57]. This reduces the extraction time.

Liquid membrane instability often cited as a major limitation of SLM extraction technique is caused by decline of analyte flux or even leakage of one aqueous phase into the other due to solvent or carrier loss during extraction. Factors such as differences in osmotic pressure between the phases and emulsion formation have been identified as causes of instability [58-61]. Gelation, in which a thin liquid film with properties of a highly swollen cross-linked polymer rather than a liquid, has been applied on the surface of the membranes to improve stability, but such an approach results in lower diffusion coefficient $[47,62]$. Another approach is forming a semipermeable skin layer on the surface of the supported-liquid membrane through either interfacial [63-65] or plasma polymerization process [62]. For analytical purposes, especially with di- $n$-hexylether or $n$-undecane as membrane liquids, SLMs are stable from a week [66] to a month $[67,68]$. Convenient regeneration of the membrane using the same hydrophobic porous support has also been demonstrated either in situ by Thordarson et al. [69] or by Dzygiel et al. [51] after demounting the support.

Three different physical realizations of SLM modules have generally been reported [54,70], i.e., the flat, spiral, and tubular modules. One important property among these modules is the ratio between membrane surface area and its volume [70]. This ratio should be high to get large enrichment factors especially for analytical purposes. It is highest for the tubular module (1000-10 000), followed by the spiral module (100-1000) and lowest for the flat module (10-100) [70]. Most research groups have used either flat module and/or hollow fiber modules with channel volumes in the range 10-1000 $\mu 1$ [14] with exception of hollow fiber design where channel volumes of less than $1.3 \mu \mathrm{l}$ have been realized [69]. However, the area of modules and versions of SLM extraction is currently enjoying much attention as seen from publications [22,24-28]. It will be discussed in detail below. Some examples of such modules and their respective channel volumes are shown in Fig. 2. They are made of inert materials such as polytetrafluoroethylene (PTFE), polyvinylidene fluoride (PVDF), or titanium. For flat modules, a groove is machined in each block, and liquid connections are provided at both ends. An impregnated membrane is clamped between the blocks, forming a channel at both sides of the membrane. The choice of the membrane material has been discussed in previous works [68,71,72]. An ideal membrane support is the one that gives high solute permeation and stable membranes. Generally, thin membranes such

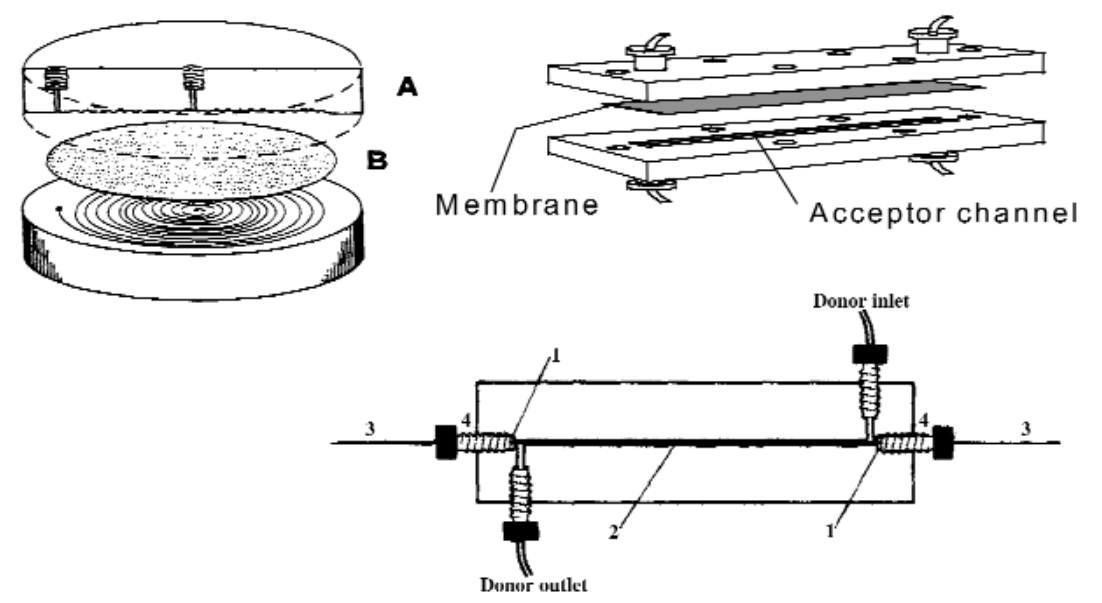

Fig. 2 (A) Membrane unit with $1 \mathrm{ml}$ channel volume (A = blocks of inert material, B = membrane). (B) Membrane unit with 10- $\mu$ l channel volume. (C) Hollow fiber membrane unit with 1.3- $\mu$ l acceptor channel (lumen) volume ( 1 = O-rings, 2 = polypropylene hollow fiber, $3=$ fused silica capillaries, $4=$ male nuts $)$. From ref. 15 with permission. 
as FGLP (Millipore) or TE 35 (Schleicher and Schuell) with small pores $(\sim 0.2 \mu \mathrm{m})$, and polyethylene backing have been used. These have been found to facilitate mass transfer and at the same time able to retain the impregnated liquid firm enough to avoid deformation due to small pressure changes in the system.

\section{Attractiveness of SLM extraction in sample preparation}

\section{Relatively easy to design modules to suit specific application}

The area of new modules is currently enjoying much attention in liquid membrane extraction. It seems the goal is achieving miniaturized, easy, and simple to operate designs [22,28]. In some cases, automation has been emphasized as an additional goal $[23,26]$. Jönsson and Mathiasson $[10,16]$ have recently reviewed many of these new configurations. Some of new versions include the extraction syringe (ESy) [23] that uses a hollow fiber; the inside is filled with an organic acceptor solution and is connected directly to gas chromatograph. Another variation of this is hollow fiber-protected liquid-phase microextraction (LPME) that operates in a similar way to solid-phase microextraction (SPME) and uses an organic acceptor solution. The emphasis of other modules is on miniaturization, simplicity, and ease of use based on the principles of SLM extraction, which include solvent microextraction and back-extraction (SME/BE) that preconcentrates into a single drop [27] and liquid-liquid-liquid-microextraction (LLL-ME). The LLL-ME uses a miniaturized hollow fiber in the form of a $U$ tube. The inside of the hollow fiber serves as the acceptor solution. Recently, the XT-tube extractor has been reported that also uses a hollow fiber and is based on the principles of SLM extraction [25]. We also reported a supportedliquid membrane probe (SLMP) [22]. This is similar to the one reported by Mullins [24]. However, in the latter case, a silicone rubber was used as a membrane instead of a liquid membrane. The SLMP consisted of a miniaturized polypropylene tube. One end of the tube was closed with the porous millipore filter sealed with PTFE tape and soaked in appropriate solvent. The inside of this probe served as acceptor solution. This is perhaps one of the simplest configurations to be reported to our knowledge.

\section{Low solvent consumption and selectivity in various matrices}

In SLM extractions using membranes, the only organic solvent needed is used to fill the pores of porous support [14] and/or part of the acceptor solution - as in microporous membrane liquid-liquid extraction (MMLLE) [73] and extraction syringe (ESy) [23]. In any of these extractions, small volumes (in most cases, less than $1 \mathrm{ml}$ ) are consumed for each extraction. A miniaturized version of any of these membrane extractions consumes even less organic solvent than given above. An example is an ESy technique with consumption volume of less than $20 \mu \mathrm{l}$ [23]. Therefore, liquid membrane-based extractions are more environmentally friendly and cheaper as the cost of buying and disposing large quantities of organic solvents common in liquid-liquid extraction or solid-phase extraction is reduced. This also allows the use of expensive carriers or solvents since only a small volume is needed.

Selectivity has always been associated with a good sample preparation technique. In SLM extraction technique, the $\mathrm{pH}$ of the donor solution and the acceptor phase can easily be fine-tuned to get selective extraction as described above [20,74]. Alternatively, a carrier can be added in the membrane as in SLM extraction to increase the selectivity and/or mass transfer of the compounds of interest. Shen et al. $[53,75]$ added TOPO in the membrane containing di- $n$-hexylether when extracting short chain carboxylic acids from soil extracts to increase the mass transfer. When the primary aim of adding a carrier is to increase the mass transfer of the analytes by analyte-carrier interactions in the membrane, it is important to choose other conditions carefully so that selectivity is still retained. This was the case when extracting both metabolites and their parent compounds of $s$-triazines from river water containing high amounts of humic substances with TOPO as a carrier [57]. In this case, it was important that possible polar interfering matrix compounds, which would also have increased mass transfer into the membrane, is not trapped in the acceptor phase. Thus, by having an acidic acceptor solution, most of the humic acids $(25 \mathrm{mg} / \mathrm{l})$ present in spiked river water were not trapped in the acceptor, giving clean chro- 
matograms [57]. In other applications [76,77], volumes of 11 river water have been extracted with SLM extraction in the determination of triazine herbicides, but still getting very clean chromatograms. Phenolic acids have also been extracted with SLM technique from nutrient solution of hydroponically growing tomato $[78,79]$. In both above cases, very clean chromatograms were obtained, stressing the selectivity of the SLM extraction. Other SLM technique applications where selectivity was demonstrated include extraction of sulfonylurea herbicides [67,72] from river water, organic acids [80] in manure, aromatic surfactants [81], and chlorophenols [82] in river water, and aniline derivatives [83] in wastewater. Recently, selectivity was studied in SLM extraction of uranium(VI) from natural water by scanning the metal ions present in the sample before SLM extraction and in the extracts after extraction by inductively coupled plasma optical emission spectrometry. Selectivity of the carrier toward uranyl ion was clearly demonstrated (Table 2). Most of the alkaline earth metal ions despite being very high concentrations in the sample were virtually not extracted [84].

Table 2 Concentrations of various metals in sample as found by ICP-OES before and after SLM extraction in the collected acceptor phase [84]. Obtained with permission from Wiley-VCH.

\begin{tabular}{lccc}
\hline Element & \multicolumn{3}{c}{ Concentration of various elements in $\mu \mathrm{g} / \mathrm{l}$} \\
\cline { 2 - 4 } & $\begin{array}{c}\text { Before SLM } \\
\text { extraction }\end{array}$ & $\begin{array}{c}\text { After SLM } \\
\text { extraction } \\
\text { in collected } \\
\text { acceptor phase }\end{array}$ & $\begin{array}{c}\text { Extraction } \\
\text { efficiency (\%) }\end{array}$ \\
\hline $\mathrm{Li}$ & $<3$ & $<0.20$ \\
$\mathrm{Mg}$ & 1600 & 36 & 0.08 \\
$\mathrm{~K}$ & 44330 & 1400 & 1.60 \\
$\mathrm{Ca}$ & 88600 & 23 & 0.11 \\
$\mathrm{Sr}$ & 21040 & 15650 & $<0.06$ \\
$\mathrm{P}$ & 7800 & $<6$ & 230 \\
$\mathrm{Ni}$ & 68 & 38 & 21 \\
$\mathrm{U}$ & 34 & & $<18$ \\
\hline
\end{tabular}

Comparing selectivity between solid-phase extraction with $\mathrm{C}_{8}, \mathrm{C}_{18}$, polymeric, or graphitized carbon black sorbents to SLM extractions, the latter are expected to give cleaner extracts. An example of this is SLM extraction of surface water that gives clean chromatograms [67,74]. By contrast, chromatograms of extraction of surface water with the above sorbents are characterized with huge hump due to humic substances that are coextracted and coeluted with the analytes $[85,86]$. However, new selective sorbents in solid-phase extraction have been investigated such as molecularly imprinted polymers [87,88] and immunosorbents [89-91], capable of giving clean extracts as well.

\section{High enrichment factors and time-integrative field sampling}

In supported-liquid membrane extractions, high enrichment factors are a result of high solubility of the analytes into the membrane and/or trapping in the acceptor phase. In the absence of any trapping in the acceptor phase, like MMLLE, high enrichment factors are limited by the partitioning into the membrane. The maximum enrichment factor in the case with a stagnant acceptor phase is equal to the partition coefficient $(K)$ of the analyte between the membrane and the aqueous sample [73]. These techniques are, therefore, suitable for extraction of neutral or uncharged (in the donor) compounds with octanol-water partition coefficients $\left(\log K_{\text {ow }}\right)$ ranging from $\sim 2.0$ to 6.0 [12,73,92]. The above polarity range includes most parent herbicides, chlorinated pesticides down to polycyclic aromatic hydrocarbons (PAHs), and polychlorinated biphenyls (PCBs) [93,94]. Norberg et al. [92] reported enrichment factors as high as 250 times when extracting cationic surfactants from river and wastewaters using MMLLE. In this case, the analytes were ion-paired with heptanoic acid and extracted at $8 \mathrm{ml} / \mathrm{min}(300 \mathrm{ml})$ into 
chlorobutane that formed the acceptor phase. In SLM extraction, the trapping in the acceptor phase allows additional enrichment. As described by a simple theory, infinitely large enrichment factors can be obtained with SLM extraction as the concentration of uncharged analyte in the acceptor is kept at zero. In reality, the high enrichment factors are limited by the processing time and/or the available sample volume. Sometimes, the $\mathrm{p} K_{\mathrm{a}}$ of the compound may also limit the enrichment factors if it does not allow complete trapping in the acceptor phase. The influence of the $\mathrm{p} K_{\mathrm{a}}$ on the enrichment factor was investigated in detail when extracting aniline derivatives and triazine herbicides [55] (Fig. 3). For compounds that were not fully trapped in the acceptor phase, the maximum enrichment factor was easily attained and was limited by the fraction of uncharged analyte in the acceptor phase $\left(\alpha_{A}\right)$ [55]. On other hand, for compounds that were completely trapped in the acceptor phase, enrichment factors up to 2000 times could be reached with 6 liter sample volume and was limited by the processing time.

In both the aquatic and air environment, it is important to obtain information on the time-weighted average (TWA) concentrations of pollutants. This is an important part of ecological risk assessment process for chemical pollutants. Besides, it is important to quantify the concentrations of freely dissolved pollutants in water for approximate characterization of the bioavailable fraction. However, concentrations of truly dissolved pollutants and time-weighted average concentrations of pollutants cannot be determined in one step by common sampling and sample preparation techniques. Very few techniques can do this, e.g., the automated system for monitoring of organic pollutants in surface water (SAMOS) [95-97]. The SAMOS automatically collects water samples from a river with a filtration device, online preconcentration with solid-phase extraction, and further analysis by either gas or liquid chromatography. A SAMOS system is, however, an expensive equipment, not easily affordable by average laboratories. Zhang et al. [98] attempted to construct a direct solid-phase microextraction (SPME) with a hollow fiber membrane protection as a field sampler. In this approach, the fiber of an SPME device was placed inside a cellulose hollow membrane, which allows target contaminants to diffuse through while excluding high-molecular-weight interfering compounds. This can be used to determine truly dissolved contaminants in aqueous samples. However, it is not suitable for long-time period sampling because of easy saturation of the analytes on the fiber despite the fact that it is selective. Pawliszyn's research group recently reported a modified solid-phase microextraction device that was used as a passive sampler to determine the time-weighted average concentrations of volatile organic

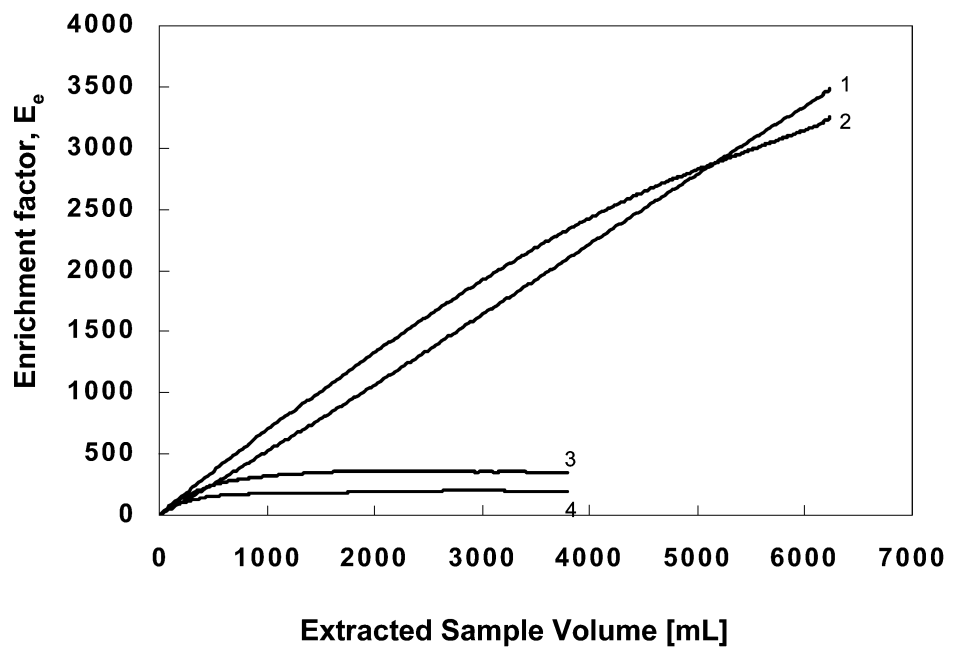

Fig. 3 Variation of enrichment factor with SLM extracted sample volume for aniline derivatives $(0.10 \mathrm{ppm})$ at different concentration of the acceptor solution: (A) $0.1 \mathrm{M}$ sulfuric acid ( $\mathrm{pH} \sim 1.0$ ); (B) $1.0 \mathrm{M}$ sulfuric acid ( $\mathrm{pH} ~ 0,0$ ). Extracted compounds; aniline (1), 3-chloro-4-methylaniline (2), 3,5-dichloroaniline (3) and 3-methyl5-nitroaniline (4). With permission from American Chemical Society [55]. 
compounds in air [99]. Another solventless and simple technique for preconcentration of organic contaminants from aqueous samples, the stir bar sorption extraction (SBSE) was used as a passive sampler [100]. The SBSE was used as a receiving phase. It was enclosed in a dialysis membrane bag made from regenerated cellulose. This approach seems very attractive, but is only amenable to compounds that are semivolatile to volatile as it uses gas chromatography for final analysis. Other membrane-based techniques have been used in determining the truly dissolved fraction of the pollutant on a time-weighted average basis. Zabiegala reported a method for calibration of permeation passive samplers with silicone membranes based on physicochemical properties of volatile analytes [101]. SPMDs [46] are perhaps the most used time-weighted average passive field samplers. They have been used for sampling organochlorine pesticides in soil for 28 days [40], PCBs, and organochlorine pesticides in water for 30 days [45] and PCBs in air for two years [43]. Their major drawback is lack of selectivity.

It is possible to use the SLM extraction technique for measuring the bioavailable fraction of pollutants and as time-integrating field sampler. This was demonstrated by Knutsson et. al [102] and Nilvé [72] who developed methods for time-integrating field sampling of acidic herbicides and 2-methyl-4chlorophenoxy acetic acid (MCPA), respectively, over $24 \mathrm{~h}$ sampling periods with detection limits down to $0.03 \mu \mathrm{g} / \mathrm{l}$. It enabled them also to monitor episodic contamination and provided information about truly dissolved time-weighted average pollutant concentrations over a long time period. One advantage with SLM extraction is that it gives much flexibility in the collection of the selectively enriched acceptor phase at any one time during extraction, which needs only to be displaced out with a fresh acceptor solution (Fig. 4). The other advantage is that there is no risk of breakthrough volume being reached since the concentration of uncharged analyte in the acceptor phase is kept at zero. The accumulation of less nutritious compounds, mostly phenolic acids, was also investigated for three months in a nutrient

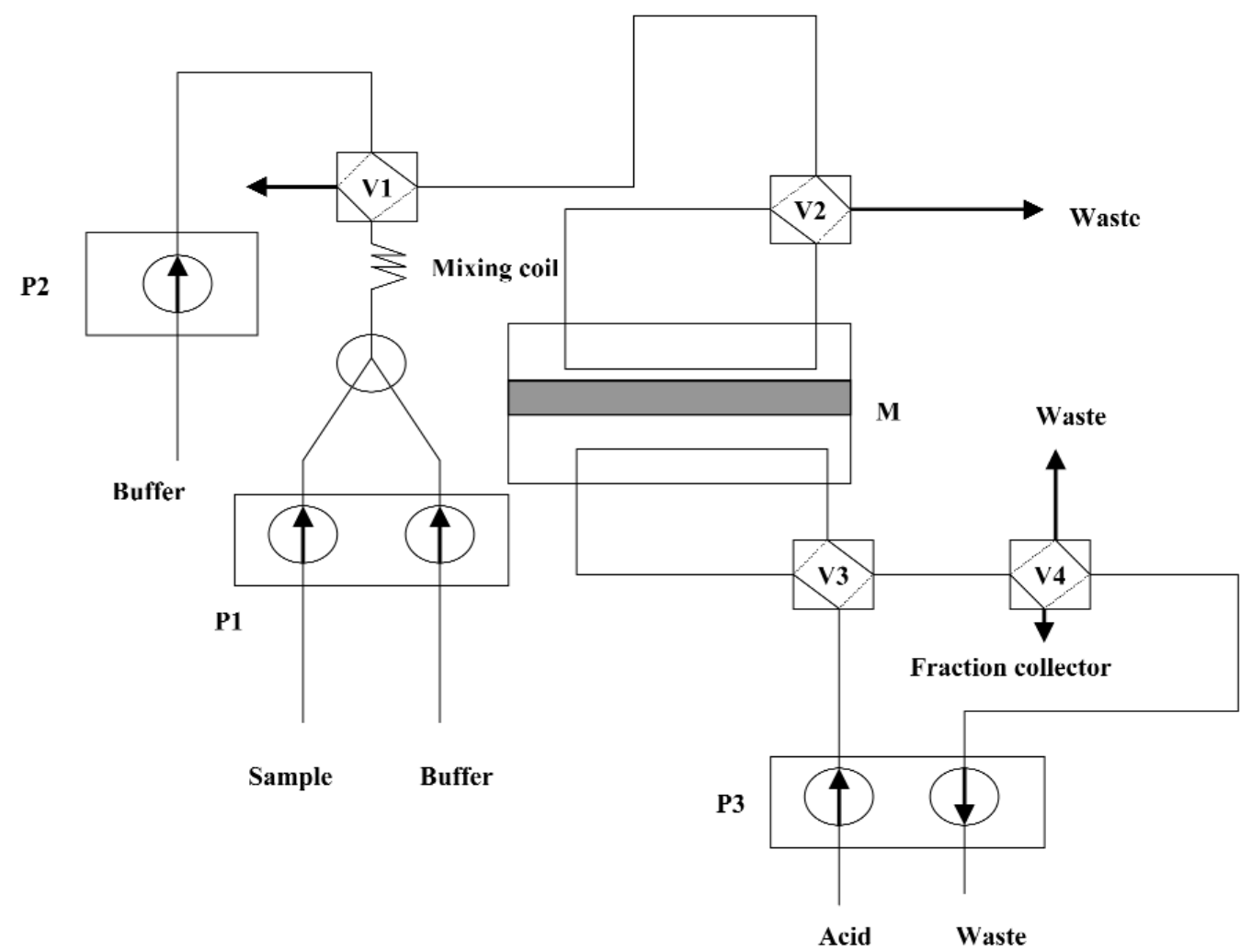

Fig. 4 Schematic diagram for automated SLM extraction, M represents membrane separator. With permission from Wiley-VCH [57]. 
solution of hydroponically growing tomato using SLM extraction by Jung et al. [79]. In this case, three parallel membrane extraction cells were used to study similarly treated nutrient solution. Extractions in each case was for $3 \mathrm{~h}$ at donor flow rate of $0.3 \mathrm{ml} / \mathrm{min}$.

\section{Automation and online extraction}

In SLM extraction membrane, automation can be either the extraction process alone or in combination with the final analytical instrument. Alternatively, the extraction process can be coupled to the analytical instrument, but not in a fully automated way. Here, extraction is done online but manual work is used to start pumps or switch on/off valves to direct the solutions in a flow system. Using SLM extraction, several automated extractions have been reported, and typical set-up is shown in Fig. 5.

Important parts of the automation system are peristaltic pumps for pumping the solutions, switch valves for directing solutions, fraction collector for collecting the extracts, and computer for programming timed control of events. Such a set-up also allows a fast way to optimize the extraction parameters since the only demand is changing the parameter and the extract is collected automatically. If the final analysis is also independently automated, then only work involved is transferring of extracts for analysis. Automated extraction was used for SLM extraction of triazines from natural water [57] and biogenic amines in wine [103]. Ndung'u et al. [104] used a similar set-up for automated extraction of organotin compounds using MMLLE.

Coupling of membrane-based extractions to final analytical instruments is not very complicated as clean extracts are obtained. Extractions that trap the analytes in an organic acceptor (e.g., MMLLE and ESy techniques) are easily interfaced with gas chromatography. Shen et al. [73] interfaced MMLLE to gas chromatography in the extractions of biological compounds from urine. Melcher [105] also interfaced PME to gas chromatography when extracting phenolic compounds. The ESy technique, on the other hand, gives direct connection to a gas chromatograph [23] since the content of the acceptor phase is directly injected into the instrument using a gas chromatographic syringe. Shen et al. [26] is also reported to have coupled a hollow fiber-protected liquid-phase micro-extraction in more or less to that of ESy technique.

It is also possible to interface membrane-based extractions to liquid chromatography. SLM extraction is ideal for this purpose since it provides an aqueous acceptor phase [82], which is also the case

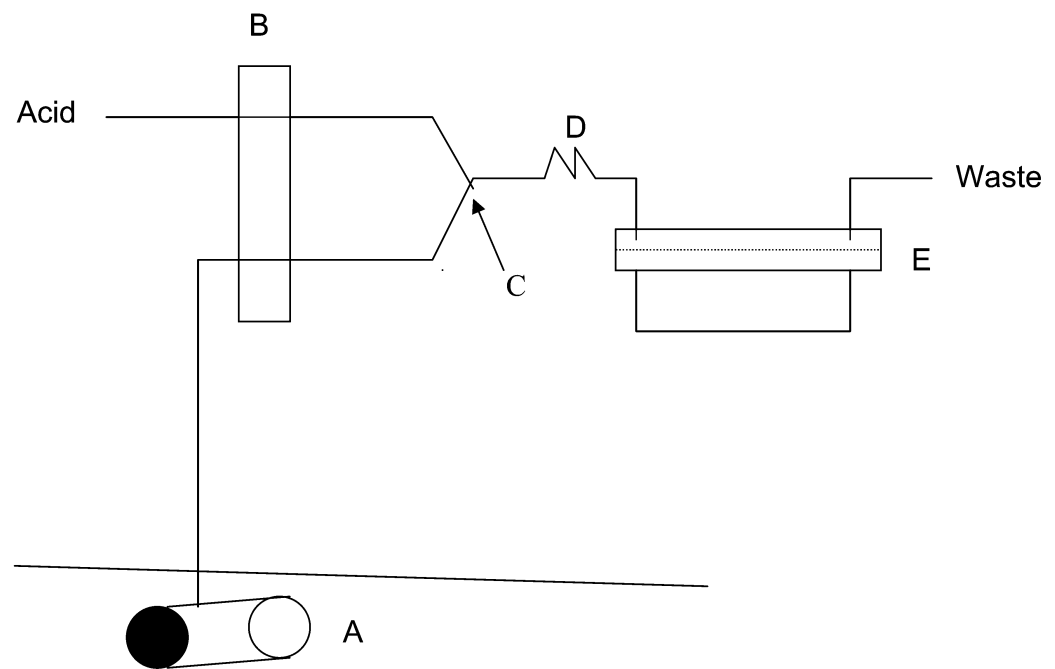

Fig. 5 Field sampling set-up for membrane enrichment of acidic herbicides in natural waters: (A) sampling point; (B) peristaltic pump; (C) confluence point of sample stream $(0.8 \mathrm{ml} / \mathrm{min})$ and a stream of $0.4 \mathrm{M}$ sulfuric acid $(0.15 \mathrm{ml} / \mathrm{min})$; (D) mixing coil; (E) membrane separator with stopped flow in the acceptor channel. With permission from American Chemical Society [67]. 
with PME [20,33], so it can be interfaced in a similar way. In some cases, this demands transferring the content of the acceptor phase to a precolumn as part of the switch valve connecting to the liquid chromatograph [82]. The analytes are transferred to the analytical column by changing the position of the valve and thereby desorbed by the mobile phase. This step allows large-volume injection of the acceptor phase, and the whole plug is injected. Further, it allows adjusting the $\mathrm{pH}$ of the extract in a flow system so that it is compatible with the precolumn and/or analytical column $[67,82]$. Such set-ups have been used for automated online extraction interfaced with liquid chromatography of sulfonylurea herbicides and chlorophenols from river water by Nilvé et al. [67,72] and Knutsson et al. [82], respectively.

Sometimes, an ordinary liquid chromatograph loop can be used in the switch valve instead of a precolumn. This is possible if the extracts do not need any $\mathrm{pH}$ adjustments before being transferred to a liquid chromatograph. It also suits miniaturized versions of membrane-based extractions that can transfer almost whole content of the acceptor plug to the loop. Otherwise, the system has to be optimized in such a way that the plug with highest concentration of the analyte is transferred to the loop. Jönsson et al. [106] interfaced an SLM extraction cell (10- $\mu 1$ channel volumes) to ion-pair chromatography via a $100-\mu 1$ switch valve loop. In this case, ropivacaine metabolites where ionized and trapped in the acceptor phase (phosphate buffer at $\mathrm{pH} 2.5$ ) compatible with chromatography separation. Norberg et al. [92] coupled MMLLE online to normal-phase liquid chromatography in a similar way via an ordinary loop in the switch valve when determining cationic surfactants in river and wastewater, but valves and pumps were controlled manually.

Coupling membrane-based extractions to capillary zone electrophoresis is another attractive technique especially because of its separation power. However, the problem is low detection limits for environmental applications since only small sample volumes can be injected. This problem was approached by using a miniaturized hollow fiber membrane device with small acceptor volume $(1-3 \mu \mathrm{l})$ to obtain high enrichment factors and injection of the whole acceptor plug online to capillary zone electrophoresis in the extraction of basic drugs [107,108].

\section{Speciation studies in biological and environmental samples}

The SLM extraction technique according to the simple theory explained already is very much suited for speciation studies in both biological and environmental samples. This is because in SLM extractions, only the freely dissolved pollutants or those weakly bound to the sample matrices are extracted. In ecological risk assessment of pollutants in the field, measuring the freely dissolved pollutants in the sample is approximated to measuring the pollutant levels in the organisms themselves. When a suitable carrier is added in the membrane, it is possible to extract the specific oxidation state of the metal ion that is freely dissolved and bioavailable in the sample. This is critical in exposure risk assessment of metal ions because the toxicity of most metals depends on their charges. Speciation studies using SLM membrane incorporating suitable carrier has been studied by Lund University (Sweden), Department of Analytical Chemistry Research Group [49,109-114]. A good example is the selective extraction and enrichment of anionic $\mathrm{Cr}(\mathrm{VI})$ and cationic $\mathrm{Cr}(\mathrm{III})$ species in two serially connected SLM units. This was achieved with methyltricaprylammonium chloride (Aliquat) and di-(2-ethyhexyl) phosphoric acid (DEHPA) as extractants, respectively [112]. However, most of these applications were made in natural water samples. Speciation studies were done only in urine samples for metal ions like lead [110,111]. Generally, it is more difficult to do speciation studies in biological samples like milk, whole blood, blood serum, and plasma because most metal ions are complexed to matrix components. Recently, attempts were made to do speciation studies for chromium(VI) in urine [52] and manganese(II) in blood serum and milk [22]. Scanning electron microscopy results of the used membranes in both cases showed that apart from the metal ions being complexed to sample matrices, the matrix itself tends to block the pores of the membrane that consists of the carrier. This results in low extraction efficiency especially for chromium(VI), perhaps because it is a big molecule compared to manganese(II). The results for manganese(II) showed strong dependence of the sample matrix, as seen in Fig. 6. 


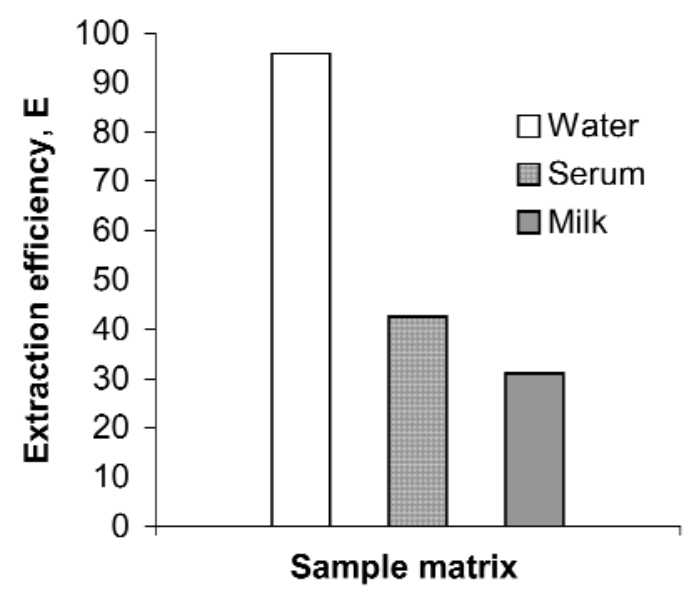

Fig. 6 Influence of sample matrix on Mn(II) extraction efficiency using an SLMP. Stirring time $=60 \mathrm{~min}$, R.S.D.; water $=10 \%$, milk $=16 \%$, serum $=15$ for $n=3$. Taken from ref. 22 with permission from Elsevier.

\section{CONCLUSIONS}

Liquid membrane-based extractions are capable of complementing conventional techniques (liquid-liquid and solid-phase extractions) in environmental and biomedical sample preparation. Their attractiveness in sample preparation is based on being able to design a configuration that can suit specific application at no cost. They offer the possibility of determining the concentration of freely dissolved pollutants on a time-weighted average basis, thus reflecting the episodic changes in real time. They are also suitable for exposure risk assessment of metal ions in both environmental and biological samples since the bioavailable fraction with its specific charge is measured. They can also be easily automated and interfaced to other separation techniques.

\section{ACKNOWLEDGMENTS}

Some of the work was done at Lund University, Department of Analytical Chemistry, Sweden and we would like to acknowledge former and present postgraduate students that were involved. Also, we would like to acknowledge financial support from both Swedish agencies, such as the Swedish Institute, the Swedish National Research Foundation and South African agencies, especially the National Research Foundation.

\section{REFERENCES}

1. J. R. Dean. Extraction Methods for Environmental Analysis, John Wiley, Chichester (1998).

2. C. F. Poole and I. D. Wilson. J. Chromatogr. A 885 (1,2), (2000).

3. H. Sabik, R. Jeannot, B. Rondeau. J. Chromatogr. A 885, 217 (2000).

4. D. T. Rossi and N. Zhang. J. Chromatogr. A 885, 97 (2000).

5. M.-C. Hennion. J. Chromatogr. A 856, 3 (1999).

6. A. Balinova. J. Chromatogr. A 754, 125 (1996).

7. M. Biziuk, A. Przyjazny, J. Czerwinski, M. Wiergowski. J. Chromatogr. A 754, 103 (1996).

8. E. M. Thurman and M. S. Mills. Solid Phase Extraction, Principles and Practice, John Wiley, New York (1998).

9. J. Beltran, F. J. López, F. Hernández. J. Chromatogr. A 885, 389 (2000).

10. J. A. Jönsson and L. Mathiasson. In Advances in Chromatography, Vol. 41, P. Brown and E. Grushka (Eds.), p. 53, Marcel Dekker, New York (2000). 
11. N. C. v. d. Merbel. J. Chromatogr. A 856, 55 (1999).

12. J. D. Petty, C. E. Orazio, J. N. Huckins, R. W. Gale, J. A. Lebo, J. C. Meadows, K. R. Echols, W.

L. Cranor. J. Chromatogr. A 879, 83 (2000).

13. L. Chimuka, N. Mergesa, J. A. Jönsson. Transworld Res. 2, 13 (2002).

14. J. Å. Jönsson and L. Mathiasson. Trends Anal. Chem. 18, 318 (1999).

15. J. Å. Jönsson and L. Mathiasson. Trends Anal. Chem. 18, 325 (1999).

16. J. Å. Jönsson and L. Mathiasson. J. Sep. Sci. 24, 495 (2001).

17. J. A. Jönsson (Ed.). Membrane Extraction in Analytical Chemistry, J. Sep. Sci., Vol. 24, WileyVCH, Weinheim (2001).

18. N. C. v. d. Merbel and U. A. T. Brinkman. Trends Anal. Chem. 12, 249 (1993).

19. A. J. J. Debets, P. v. Wier, K.-P. Hupe, U. A. T. Brinkman, W. T. Kok. Chromatographia 39, 460 (1994).

20. R. C. Martínez, E. R. Gonzalo, E. H. Fernandez, J. H. Mendez. Anal. Chim Acta 304, 323 (1995).

21. M. A. Jeannot and F. F. Cantwell. Anal. Chem. 69, 235 (1997).

22. L. Soko, L. Chimuka, E. Cukrowska, S. Pole. Anal. Chim. Acta 485, 25 (2003).

23. J. Norberg and E. Thordarson. Analyst 125, 673 (2000).

24. F. Mullins. J. Sep. Sci. 24, 593 (2001).

25. O. B. Jonsson, U. Nordlöf, U. L. Nilsson. Anal. Chem. 75, 3506 (2003).

26. G. Shen and H. K. Lee. Anal. Chem. 74, 648 (2002).

27. M. Ma and F. F. Cantwell. Anal. Chem. 71, 1879 (1999).

28. S. Pedersen-Bjergaard and K. E. Rasmussen. Anal. Chem. 71, 2650 (1999).

29. N. C. v. d. Merbel, J. J. Hageman, U. A. T. Brinkman. J. Chromatogr. 634, 1 (1993).

30. M. M. L. Aerts, W. M. J. Beek, U. A. T. Brinkman, J. Chromatogr. 500, 453 (1990).

31. M. G. M. Groenewegen, N. C. v. d. Merbel, J. Slobodnik, H. Lingeman, U. A. T. Brinkman. Analyst 119, 1753 (1994).

32. S. D. Doig, A. T. Boam, A. G. Livingston, D. C. Stuckey. J. Membr. Sci. 154, 127 (1999).

33. R. G. Melcher, D. W. Bakke, G. H. Hughes. Anal. Chem. 64, 2258 (1992).

34. R. C. Martínez, E. R. Gonzalo, J. D. Alvarez, J. H. Méndez. J. Chromatogr. A 869, 451 (2000).

35. R. G. Melcher. Anal. Chim. Acta 214, 299 (1988).

36. K. F. Pratt and J. Pawliszyn. Anal. Chem. 64, 2101 (1992).

37. Y. Z. Luo, M. Adams, J. Pawliszyn. Anal. Chem. 70, 248 (1998).

38. M. Harper. J. Chromatogr. A 885, 129 (2000).

39. H. Lord, Y. Yu, A. Segal, J. Pawliszyn. Anal. Chem. 74, 5650 (2002).

40. B. Strandberg, N. Wägman, P.-A. Bergqvist, P. Haglund, C. Rappe. Environ. Sci. Technol. 31, 2960 (1997).

41. R. W. Gale, J. D. Petty, P. H. Peterman, L. L. Williams, D. Morse, T. R. Schwartz, D. E. Tillitt. Environ. Sci. Technol. 31, 178 (1997).

42. J. C. Meadows, K. R. Echols, J. N. Huckins, F. A. Borsuk, R. F. Carline, D. E. Tillitt. Environ. Sci. Technol. 32, 1847 (1998).

43. W. A. Ockenden, A. J. Sweetman, H. F. Prest, E. Steinnes, K. C. Jones. Environ. Sci. Technol. 32, 2795 (1998).

44. J. N. Huckins, J. D. Petty, C. E. Orazio, J. A. Lebo, R. C. Clark, W. R. Gala, K. R. Echols. Environ. Sci. Technol. 33, 3918 (1999).

45. C. S. Hofelt and D. Shea. Environ. Sci. Technol. 31, 154 (1997).

46. D. Sabaliunas, J. Lazutka, I. Sabaliuniene, A. Södergren. Environ. Toxicol. Chem. 17, 1815 (1998).

47. M. Mulder. Basic Principles of Membrane Technology, Kluwer Academic, Dordrecht (1996).

48. B. D. Smith and S. J. Gardiner. In Advances in Supramolecular Chemistry: Facilitated Transport of Small Hydrophilic Biomolecules through Artificial Membranes, Vol. 5, G. W. Gokel (Ed.), Chap. 4, JAI Press, Greenwich (1999). 
49. N. Djane, K. Ndung'u, F. Malcus, G. Johansson, L. Mathiasson. Fresenius' J. Anal. Chem. 358, 822 (1997).

50. P. Wieczorek, J. Å. Jönsson, L. Mathiasson. Anal. Chim. Acta 346, 191 (1997).

51. P. Dzygiel, P. Wieczorek, L. Mathiasson, J. A. Jönsson. Anal. Lett. 31, 1261 (1998).

52. L. Soko, E. Cukrowska, L. Chimuka. Anal. Chim. Acta 474, 59 (2002).

53. Y. Shen, V. Obuseng, L. Grönberg, J. Å. Jönsson. J. Chromatogr. A 725, 189 (1996).

54. J. Å. Jönsson, P. Lövkvist, G. Audunsson, G. Nilvé. Anal. Chim. Acta 277, 9 (1993).

55. L. Chimuka, N. Mergessa, J. Norberg, L. Mathiasson, J. Å. Jönsson. Anal. Chem. 70, 3906 (1998).

56. L. Chimuka, L. Mathiasson, J. Å. Jönsson. Anal. Chim. Acta 416, 77 (2000).

57. N. Megersa, L. Chimuka, T. Solomon, J. A.. Jönsson. J. Sep. Sci. 24, 567 (2001).

58. A. M. Neplenbroek, D. Bargeman, C. A. Smolders. J. Membr. Sci. 67, 121 (1992).

59. A. M. Neplenbroek, D. Bargeman, C. A. Smolders. J. Membr. Sci. 67, 133 (1992).

60. A. M. Neplenbroek, D. Bargeman, and C. A. Smolders. J. Membr. Sci. 67, 149 (1992).

61. F. F. Zha, H. G. L. Coster, A. G. Fane. J. Membr. Sci. 93, 255 (1994).

62. X. J. Yang, A. G. Fane, J. Bi, H. J. Griesser. J. Membr. Sci. 168, 29 (2000).

63. Y. Wang, Y. S. Thio, F. M. Doyle. J. Membr. Sci. 147, 109 (1998).

64. A. J. B. Kemperman, H. H. M. Rolevink, D. Bargeman, T. v. d. Boomgaard, H. Strathmann. J. Membr. Sci. 138, 43 (1998).

65. M. C. Wijers, M. Jin, M. Wessling, H. Strathmann. J. Membr. Sci. 147, 117 (1998).

66. G. Audunsson. Anal. Chem. 60, 1340 (1988).

67. G. Nilvé, M. Knutsson, J. Å. Jönsson. J. Chromatogr. A 688, 75 (1994).

68. B. Lindegård. Ph.D. thesis, Lund University, Sweden (1994).

69. E. Thordarson, S. Pálmarsdóttir, L. Mathiasson, J. Å. Jönsson. Anal. Chem. 68, 2559 (1996).

70. W. Kaminski and W. Kwapinski. Pol. J. Environ. Sci. Stud. 9, 37 (2000).

71. G. Audunsson. Anal. Chem. 58, 2714 (1986).

72. G. Nilvé and R. Stebbins. Chromatographia 32, 269 (1991).

73. Y. Shen, J. Å. Jönsson, L. Mathiasson. Anal. Chem. 70, 1946 (1998).

74. N. Megersa, T. Solomon, J. Å. Jönsson. J. Chromatogr. A 830, 203 (1999).

75. Y. Shen, L. Ström, J. Å. Jönsson, G. Tyler. Soil Biol. Biochem. 28, 1163 (1996).

76. N. Megersa and J. Å. Jönsson. Analyst 123, 225 (1998).

77. N. Megersa, T. Solomon, B. S. Chandravanshi, J. Å. Jönsson. Bull. Chem. Soc. Ethiop. 14, 9 (2000).

78. M. Knutsson, J. Lundh, L. Mathiasson, J. Å. Jönsson, P. Sundin. Anal. Lett. 29, 1619 (1996).

79. V. Jung, L. Chimuka, J. Å. Jönsson, N. Niedack, P. Bowens, B. Alsanius. Anal. Chim. Acta 474, 49 (2002).

80. L. Mathiasson, M. Knutsson, G. Bremle, L. Mårtensson. Swedish J. Agric. Res. 21, 147 (1991).

81. T. Miliotis, M. Knutsson, J. Å. Jönsson, L. Mathiasson. Intern. J. Environ. Anal. Chem. 64, 35 (1996).

82. M. Knutsson, L. Mathiasson, J. Å. Jönsson. Chromatographia 42, 165 (1996).

83. J. Norberg, A. Zander, J. Å. Jönsson. Chromatographia 46, 483 (1997).

84. L. Chimuka, E. Cukrowska, L. Soko, K. Naike. J. Sep. Sci. 26, 601 (2003).

85. N. Masqué, M. Galiá, R. M. Marcé, F. Borrull. J. High Resolut. Chromatogr. 22, 547 (1999).

86. V. Pichon, M. Charpak, M.-C. Hennion. J. Chromatogr. A 795, 83 (1998).

87. D. Stevenson. Trends Anal. Chem. 18, 154 (1999).

88. B. Sellergren. Trends Anal. Chem. 18, 164 (1999).

89. A. Martin-Esteban, P. Kwasowski, D. Stevenson. Chromatographia 45, 364 (1997).

90. S. Herrera, A. Martin-Esteban, P. Fernández, D. Stevenson, C. Cámara. Fresenius' J. Anal. Chem. 362, 547 (1998).

91. V. Pichon, M. Bouzige, M.-C. Hennion. Anal. Chim. Acta 376, 21 (1998). 
92. J. Norberg, E. Thordarson, L. Mathiasson, J. Å. Jönsson. J. Chromatogr. A 869, 523 (2000).

93. J. Kanazawa. Pestic. Sci. 12, 417 (1981).

94. G. G. Briggs. J. Agric. Food Chem. 29, 1050 (1981).

95. P. J. v. Hout and U. A. T. Brinkman. Trends Anal. Chem. 13, 382 (1994).

96. U. A. T. Brinkman, J. Slobodnik, J. J. Vreuls. Trends Anal. Chem. 13, 373 (1994).

97. M. Purvis, S. J. Gledhill, B. E. Drage, A. C. Hogenboom, D. A. Jolly, R. J. J. Vreuls, U. A. T. Brinkman. Intern. J. Environ. Anal. Chem. 74, 135 (1999).

98. X. Zhang, K.-W. Schramm, B. Henkelmann, C. Klimm, A. Kaune, A. Kettrup, P. Lu. Anal. Chem. 71, 3838 (1999).

99. Y. Chen and J. Pawliszyn. Anal. Chem. 75, 2004 (2003).

100. B. Vrana, P. Popp, A. Paschke, G. Schüürmann. Anal. Chem. 73, 5191 (2001).

101. B. Zabiegala, T. Górecki, J. Namiesnik. Anal. Chem. (2003). In press.

102. M. Knutsson, G. Nilvé, L. Mathiasson, J. Å. Jönsson. J. Agric. Food Chem. 40, 2413 (1992).

103. R. Romero, J. Å. Jönsson, D. Gázquez, M. G. Bagur, M. Sánchez-Vinas. J. Sep. Sci. 25, 584 (2002).

104. K. Ndung'u and L. Mathiasson. Anal. Chim. Acta 404, 319 (2000).

105. R. G. Melcher and P. L. Morabito. Anal. Chem. 62, 2183 (1990).

106. J. Å. Jönsson, M. Andersson, C. Melander, J. Norberg, E. Thordarson, L. Mathiasson. J. Chromatogr. A 870, 151 (2000).

107. S. Pálmarsdóttir, L. Mathiasson, J. Å. Jönsson, L. E. Edholm. J. Chromatogr. B 688, 127 (1996).

108. S. Pálmarsdóttir, E. Thordarson, L.-E. Edholm, J. Å. Jönsson, L. Mathiasson. Anal. Chem. 69, 1732 (1997).

109. N.-K. Djane. Ph.D. thesis, Lund University, Sweden (1997).

110. N. K. Djane, I. A. Bergdahl, K. Ndung'u, A. Schütz, G. Johansson, L. Mathiasson. Analyst 122, 1073 (1997).

111. N. K. Djane, S. Armalis, K. Ndung'u, G. Johansson, L. Mathiasson. Analyst 123, 393 (1998).

112. N. Djane, K. Ndung'u, C. Johnsson, H. Sartz, T. Törnström, L. Mathiasson. Talanta 48, 1121 (1999).

113. K. Ndung'u, N.-K. Djane, L. Mathiasson. J. Chromatogr. A 826, 103 (1998).

114. K. Ndung'u, N.-K. Djane, F. Malcus, L. Mathiasson. Analyst 124, 1367 (1999).

115. J. Å. Jönsson and L. Mathiasson. Trends Anal. Chem. 11, 106 (1992). 